\title{
Utjecaj modifikacije višestjenih ugljikovih nanocjevčica na svojstva poliuretana: I. Morfologija i toplinska svojstva
}

DOI: $10.15255 /$ KUI.2016.044 KUI-9/2017

Izvorni znanstveni rad

Prispjelo 18. studenoga 2016.

Prihvaćeno 22. veljače 2017.

\author{
S. Lučić Blagojević, a* M. Zeljko i A. Pustak ${ }^{\mathrm{b}}$ \\ a Fakultet kemijskog inženjerstva i tehnologije Sveučilišta u Zagrebu, \\ Marulićev trg 19, 10000 Zagreb \\ b Institut Ruđer Bošković, Bijenička cesta 54, 10000 Zagreb
}

\begin{abstract}
|| Sažetak
U ovom radu istraživan je učinak dodatka višestjenih ugljikovih nanocjevčica (MWCNT) te MWCNT-a modificiranog skupinama $\mathrm{COOH}(\mathrm{MWCNT}-\mathrm{COOH})$ u rasponu masenih udjela od 0 do $4 \%$ na svojstva termoplastičnog poliuretana (PU). Uzorci nanokompozita pripravljani su postupkom polaganog sušenja iz smjese poliuretana i nanopunila $u$ acetonu pri sobnoj temperaturi. Učinak dodatka nanopunila na sferolitnu morfologiju poliuretana te raspodijeljenost nanopunila u matrici PU analizirana je optičkom polarizacijskom mikroskopijom. Toplinska svojstva u neizotermnim i izotermnim uvjetima istraživana su diferencijalnom pretražnom kalorimetrijom (DSC). Optička polarizacijska mikroskopija pokazala je da dodatak oba punila razrušava krupnu sferolitnu morfologiju poliuretana. Utvrđeno je da je modificirani MWCNT-COOH bolje dispergiran u masi uzorka nego čisti MWCNT. Rezultati DSC-a pokazali su da u neizotermnim uvjetima do određenog udjela dodatak obje vrste MWCNT-a ubrzava kristalizaciju mekog segmenta poliuretana, pri čemu je ubrzanje kristalizacije izraženije u sustavima s punilom MWCNT. Vrijednosti entalpija kristalizacije pokazuju da punilo MWCNT, unatoč lošijoj raspodijeljenosti u masi uzorka, znatnije ometa kristalizaciju mekog segmenta PU-a nego MWCNT-COOH. U uvjetima izotermne kristalizacije punilo MWCNT također znatnije ubrzava kristalizaciju poliuretana nego MWCNT-COOH.
\end{abstract}

\author{
\| Ključne riječi \\ Poliuretan, ugljikove nanocjevčice, nanokompoziti, morfologija, kristalnost, toplinska svojstva
}

\section{Uvod}

Poliuretanski elastomeri su blok-kopolimeri, koji se sastoje od krutog i fleksibilnog segmenta. Zbog razlike u polarnosti odnosno termodinamičke nekompatibilnosti, ti segmenti se razdvajaju u meku i tvrdu fazu. Zahvaljujući strukturi, poliuretanski elastomeri imaju superiorna svojstva povezana s visokom tvrdoćom s obzirom na modul, visokom otpornošću na abraziju, izvrsnim mehaničkim svojstvima te biokompatibilnosti i stoga imaju iznimno široku primjenu u području adheziva, optoelektronike, biotehnologije i brojnim drugim. ${ }^{1,2}$

U novije vrijeme područje polimernih nanokompozita predmet je brojnih istraživanja. Polimerni nanokompoziti višefazni su sustavi u kojima je polimerna matrica kontinuirana faza, a diskontinuirana faza je punilo kojem je najmanje jedna dimenzija reda veličine nanometra. Utjecaj punila na svojstva kompozitnog materijala ovisi o kemijskoj i morfološkoj strukturi, veličini čestica, specifičnoj površini i međudjelovanjima s polimernom matricom. Nanopunila u odnosu na mikropunila zbog malih dimenzija čestica i velike specifične površine, a time i poboljšanog kontakta s polimernom matricom već pri malim udjelima ostvaruju značajne promjene u strukturi, morfologiji i svojstvima polimerne matrice. ${ }^{3}$ Međupovršina između polimerne matrice i punila od iznimne je važnosti za svojstva kompozita.

*Autor za dopisivanje: prof. dr. sc. Sanja Lučić Blagojević e-pošta: slucic@fkit.hr
Naša ranija istraživanja pokazala su da se inženjerstvom površine punila mogu krojiti svojstva međupovršine polimer/punilo i tako optimirati svojstva materijala u cjelini. ${ }^{4-6}$

Ugljikove nanocjevčice, uz slojevita nanopunila, kvantne točke $\mathrm{i}$ istoosna nanopunila predstavljaju značajnu skupinu nanopunila koja se istražuju kao dodatci polimernim materijalima. ${ }^{3,7}$ Ovisno o broju smotanih grafenskih listova, ugljikove nanocjevčice dijele se u dvije velike skupine: jednostjene (SWCNT) i višestjene (MWCNT). Zbog jedinstvene strukture imaju iznimna mehanička i električna svojstva te toplinsku vodljivost i stabilnost. ${ }^{8}$

Ranija istraživanja pokazala su da dodatak ugljikovih nanocjevčica može povisiti staklište amorfnih polimera ${ }^{9,10}$ te da ubrzava kristalizaciju brojnih djelomično kristalnih polimera, ${ }^{11-15}$ primjerice polilaktida, polipropilena, polikaprolaktona, polibutilen-sukcinata ili poliuretana. Osim toga, modifikacija površine ugljikovih nanocjevčica predstavlja značajan smjer prema poboljšanju svojstava koja se mogu ostvariti dodatkom tog nanopunila. Modifikacijom površine ugljikovih nanocjevčica može se smanjiti agregiranost nanopunila te poboljšati njihova raspodijeljenost i međudjelovanja s polimernom matricom što također utječe na svojstva. ${ }^{11,16,17}$

Cilj ovog rada bio je istražiti učinak dodatka ugljikovih nanocijevčica te njihove modifikacije skupinama $\mathrm{COOH}$ na morfologiju i raspodijeljenost tih nanopunila u elastomernoj poliuretanskoj matrici kao i njihov učinak na toplinska svojstva u izotermnim i neizotermnim uvjetima. 


\section{Eksperimentalni dio}

\subsection{Materijali}

Za pripravu nanokompozita upotrijebljen je termoplastični linearni hidroksil-poliuretan komercijalnog naziva Desmocoll 621 proizvođača Bayer, Njemačka. Kao nanopunila upotrijebljene su nemodificirane višestjene ugljikove nanocjevčice (MWCNT) i višestjene ugljikove nanocjevčice modificirane skupinama $\mathrm{COOH}$ (MWCNT-COOH). Uzorak MWCNT-a proizvođača Chengdu Organic Chemicals Co. Ltd., Kina, čistoće je $85 \%$. Unutarnji promjer MWCNT-a u rasponu je $5-15 \mathrm{~nm}$, a vanjski promjer $>50 \mathrm{~nm}$. Duljina nanocjevčica je $10-20 \mu \mathrm{m}$, a specifična površina im je $40 \mathrm{~m}^{2} \mathrm{~g}^{-1}$. Uzorak MWCNT-COOH proizvođača Chengdu Organic Chem. Co., Chinese Academy of Sciences, sadrži nanocjevčice promjera od 10 do $30 \mathrm{~nm}$ i dužine od 10 do $30 \mu \mathrm{m}$. Čistoća tog uzorka veća je od $90 \%$, a maseni udio skupina $\mathrm{COOH}$ iznosi 1,55 \% odnosno površinska prekrivenost s obzirom na množinu iznosi $8-10 \%$.

\subsection{Priprava nanokompozita PU/MWCNT}

Uzorci nanokompozita PU pripravljeni su postupkom iz acetona. Određena količina punila izvagana je i pomiješana s $45 \mathrm{ml}$ acetona, zatim je smjesa dispergirana ultrazvukom u trajanju od 45 min. Nakon dispergiranja dodana je određena količina poliuretana te je uzorak tri sata homogeniziran na magnetskoj miješalici brzinom 300 okretaja u minuti. Homogenizirana smjesa sušena je u poklopljenim Petrijevim zdjelicama da se spriječi naglo isparavanje acetona, što bi uzrokovalo poroznost u strukturi uzoraka. Uzorak je sušen do konstantne mase. Tim postupkom pripravljeni su uzorci PU-a i kompozita s masenim udjelima oba punila od 0,$2 ; 0,5 ; 1,0 ; 2,0 ; 3,0$ i $4,0 \%$.

\subsection{Karakterizacija nanopunila}

\subsubsection{Odredivanje kontaktnog kuta s vodom}

Promjene u svojstvima površine uzrokovane modifikacijom površine punila MWCNT sa skupinama $\mathrm{COOH}$ analizirane su tehnikom kontaktnog kuta s vodom. Uzorci punila MWCNT i MWCNT-COOH dispergirani su u kloroformu ultrazvukom te je zatim disperzija nanesena na predmetno stakalce. Nakon isparavanja otapala dobiven je sloj uzorka (slika 1) na kojem je određivan kontaktni kut s kapi vode s pomoću goniometra OCA 200 Data Physics Contact Angle System. Volumen kapi iznosio je $6 \mu$ l. Mjerenja su ponovljena za svaki uzorak 3 puta te je odgovarajućim programskim paketom određen kontaktni kut s kapljicom vode.

\subsubsection{Dispergiranje u acetonu}

Istražen je učinak modifikacije površine MWCNT-a sa skupinama $\mathrm{COOH}$ na sposobnost dispergiranja u acetonu. Aceton je izabran jer su nanokompozitni sustavi PU pripravljani iz otopine acetona. $U$ tu svrhu odvagano je $5 \mathrm{mg}$ uzoraka MWCNT ili MWCNT-COOH te im je dodano $20 \mathrm{ml}$ acetona. Uzorci su dispergirani ultrazvukom u trajanju od 45 min te je praćena stabilnost disperzije nakon $2 \mathrm{~h}$.
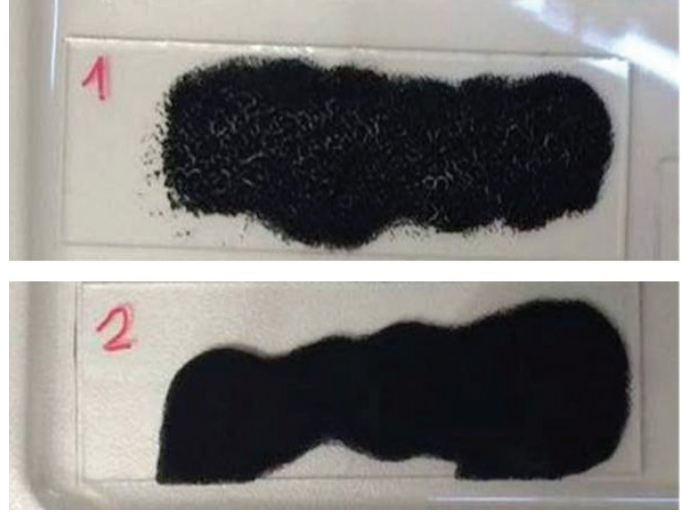

Slika 1 - Sloj uzoraka ugljikovih nanocjevčica: 1) MWCNT i 2) MWCNT-COOH

Fig. 1 - Layer of carbon nanotubes samples: 1) MWCNT and 2) MWCNT-COOH

\subsection{Karakterizacija nanokompozita PU/MWCNT i PU/MWCNT-COOH}

\subsubsection{Optička polarizacijska mikroskopija}

Morfologija pripravljenih nanokompozitnih uzoraka istražena je polarizacijskim mikroskopom Leica (model DMLS) opremljenim analognom kamerom Sony. Tanki uzorci nanokompozita izrezani su skalpelom, stavljeni na stakalce, fiksirani cedrovim uljem i pokriveni pokrovnim stakalcem.

\subsubsection{Toplinska svojstva u neizotermnim uvjetima}

Toplinska svojstva nanokompozita PU/MWCNT i PU/ MWCNT-COOH pri neizotermnim uvjetima istraživana su diferencijalnom pretražnom kalorimetrijom (DSC), na instrumentu DSC 823e Mettler Toledo. Uređaj je kalibriran testom taljenja indija kojem je poznata vrijednost temperature i entalpije taljenja. Toplinska svojstva polimerne matrice i pripravljenih kompozita u neizotermnim uvjetima istražena su eksperimentom kako slijedi. Uzorak je najprije ohlađen od sobne temperature do $-90{ }^{\circ} \mathrm{C}$, a zatim je zagrijavan od $-90{ }^{\circ} \mathrm{C}$ do $80{ }^{\circ} \mathrm{C}$ brzinom $10{ }^{\circ} \mathrm{C} \mathrm{min}{ }^{-1}$, kako bi se izbrisala njegova toplinska povijest. Nakon izotermne stabilizacije pri $80^{\circ} \mathrm{C}$ u trajanju od $3 \mathrm{~min}$, provedeno je hladenje od $80{ }^{\circ} \mathrm{C}$ do $-90{ }^{\circ} \mathrm{C}$ brzinom $10{ }^{\circ} \mathrm{C} \mathrm{min}{ }^{-1}$ pri čemu je praćena kristalizacija uzorka. Nakon izotermne stabilizacije pri $-90{ }^{\circ} \mathrm{C}$ u trajanju od 3 min uzorak je ponovno zagrijavan od $-90{ }^{\circ} \mathrm{C}$ do $80{ }^{\circ} \mathrm{C}$ brzinom $10{ }^{\circ} \mathrm{C}$ min $^{-1}$ pri čemu je praćen proces hladne kristalizacije i taljenja nastale kristalne faze. Mjerenja su provedena u struji dušika uz protok $50 \mathrm{ml} \mathrm{min}^{-1}$. Eksperimentalno dobivene vrijednosti entalpija kristalizacije i taljenja kompozita preračunate su tako da uključuju samo udio matrice PU u uzorku.

\subsubsection{Toplinska svojstva u izotermnim uvjetima}

Izotermna kristalizacija PU-a i nanokompozitnih sustava pri temperaturi $-3{ }^{\circ} \mathrm{C}$ istražena je diferencijalnom pretražnom kalorimetrijom (DSC), na instrumentu DSC 823e Mettler Toledo eksperimentom u kojem je uzorak zagrijavan od 25 do $80{ }^{\circ} \mathrm{C}$ brzinom $10{ }^{\circ} \mathrm{C} \mathrm{min}{ }^{-1}$. Nakon izoter- 
mne stabilizacije pri $80{ }^{\circ} \mathrm{C}$ u trajanju od 3 min provedeno je hlađenje do temperature izotermne kristalizacije od $-3{ }^{\circ} \mathrm{C}$ većom brzinom $\left(50{ }^{\circ} \mathrm{C} \mathrm{min}^{-1}\right.$ ) kako bi se u toj fazi spriječila kristalizacija. Izotermna kristalizacija pri $-3{ }^{\circ} \mathrm{C}$ praćena je u vremenu $25 \mathrm{~min}$. Mjerenja su provedena $u$

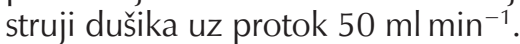

\section{Rezultati i rasprava}

\subsection{Svojstva površine ugljikovih nanocjevčica}

Svojstva površine višestjenih ugljikovih nanocjevčica određena su metodom kontaktnog kuta. Za uzorke MWCNT, MWCNT-COOH i staklo određen je kontaktni kut s vodom. Osim mjerenja kontaktnog kuta vode s uzorcima ugljikovih nanocjevčica određen je i kontaktni kut vode sa staklom kako bi se uklonila mogućnost da je na mjerenja utjecala poroznost filmova uzoraka nanocjevčica. Na slici 2 prikazane su slike kapi vode na površini filma ispitivanih uzoraka, a u tablici 1 nalaze se vrijednosti izmjerenih kontaktnih kutova.

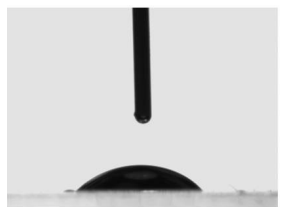

staklo / glass

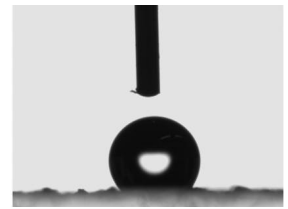

MWCNT

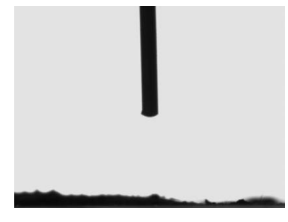

MWCNT-COOH
Slika 2 - Kapi vode na staklu i filmovima uzoraka ugljikovih nanocjevčica

Fig. 2 - Drops of water on the glass and layers of carbon nanotubes

Tablica 1 - Vrijednosti kontaktnih kutova za uzorke

Table 1 - Contact angle value of samples

\begin{tabular}{l|c|c|c|c}
\hline $\begin{array}{l}\text { Uzorak } \\
\text { Sample }\end{array}$ & $\theta_{1} /{ }^{\circ}$ & $\theta_{2} /{ }^{\circ}$ & $\theta_{3} /{ }^{\circ}$ & $\theta_{\mathrm{sr}} /{ }^{\circ}$ \\
\hline $\begin{array}{l}\text { staklo } \\
\text { glass }\end{array}$ & 49,3 & 48,4 & 45,2 & 47,7 \\
MWCNT & 140,8 & 144,3 & 140,0 & 141,7 \\
MWCNT-COOH & 0 & 0 & 0 & 0 \\
\hline
\end{tabular}

Iz dobivenih rezultata vidljivo je da se kontaktni kutovi za punila MWCNT i MWCNT-COOH znatno razlikuju. Vrijednosti kontaktnih kutova za uzorke pokazuju da se voda na površini punila MWCNT-COOH potpuno razlijeva te vrijednost kontaknog kuta iznosi $0^{\circ}$, što se pripisuje polarnosti MWCNT-COOH. Skupine $\mathrm{COOH}$ koje su procesom modifikacije vezane na površinu ugljikovih nanocjevčica nalaze se u malom broju, ali ipak čine njihovu površinu hidrofilnom. Za razliku od MWCNT-COOH-a, MWCNT su nepolarne i čine s polarnom vodom velik kontaktni kut oko $141^{\circ}$. Rezultati pokazuju da modifikacija površine MWCNT-a sa skupinama $\mathrm{COOH}$ znatno utječe na svojstva površine ugljikovih nanocjevčica.

\subsection{Dispergiranje u acetonu}

Slika 3 prikazuje disperzije uzoraka dva sata nakon provedenog dispergiranja u acetonu.

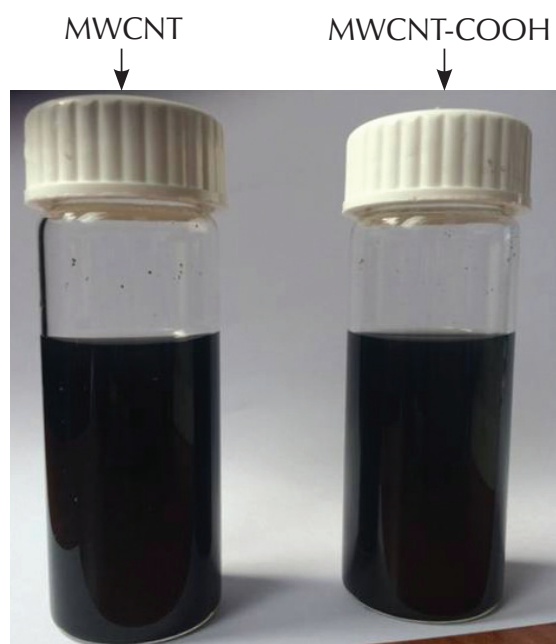

Slika 3 - Disperzije uzoraka MWCNT i MWCNT-COOH u acetonu

Fig. 3 - Dispersions of MWCNT and MWCNT-COOH samples in acetone

U acetonu koji je znatno manje polarno otapalo nego voda, unatoč razlici u kontaktnim kutovima MWCNT i MWCNT-COOH uzoraka s vodom, nema vidljive razlike u njihovoj dispergiranosti u acetonu.

\subsection{Morfologija i homogenost sustava PU}

Morfologija pripravljenih kompozita te raspodijeljenost ugljikovih nanocjevčica istraživana je optičkim polarizacijskim mikroskopom. Mikrografija PU-a (slika 4) pokazuje homogenu, dobro razvijenu sferolitnu morfologiju.

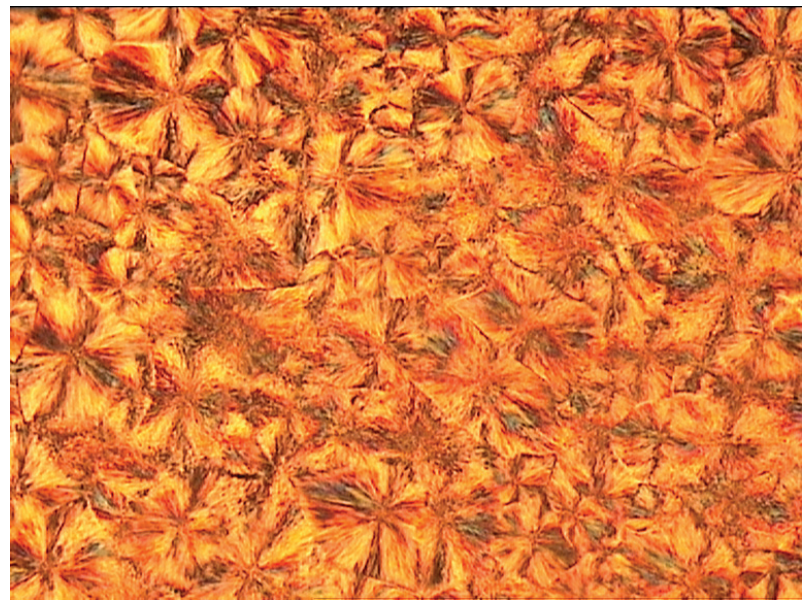

Slika 4 - Optička polarizacijska mikrografija poliuretana (povećanje $20 \times)$

Fig. 4 - Optical polarization micrograph of polyurethane (magnification $20 \times$ ) 
a) PU/MWCNT 0,2\%

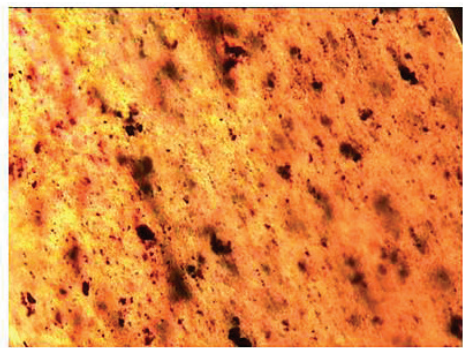

d) PU/MWCNT-COOH 0,2\%

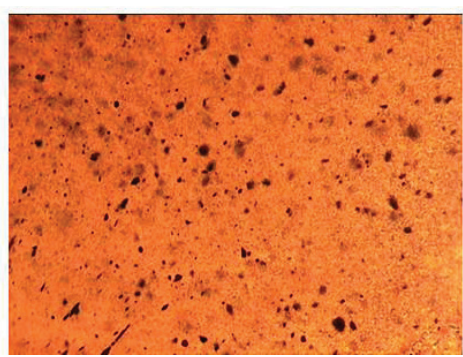

b) PU/MWCNT $1 \%$

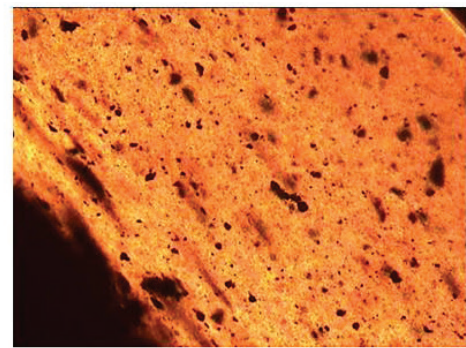

e) PU/MWCNT-COOH $1 \%$

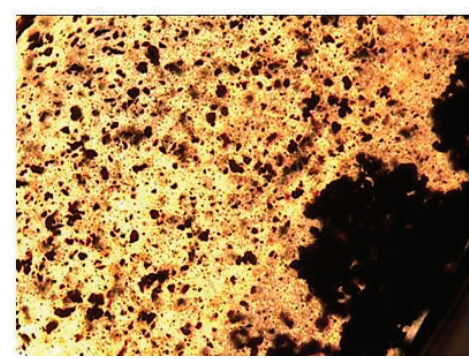

c) PU/MWCNT $3 \%$

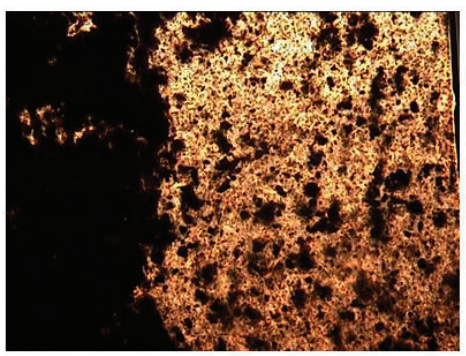

f) $\mathrm{PU} / \mathrm{MWCNT}-\mathrm{COOH} 3 \%$

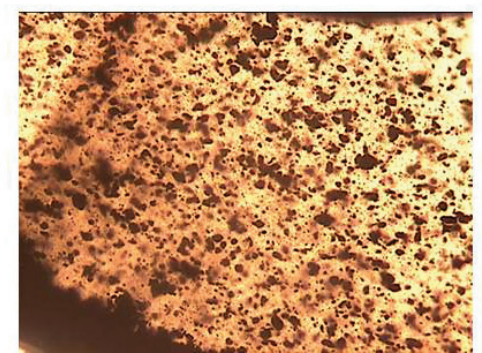

Slika 5 - Optičke polarizacijske mikrografije nanokompozita (povećanje $20 \times$ )

Fig. 5 - Optical polarization micrographs of nanocomposites (magnification $20 \times$ )

Polarizacijske mikrografije odabranih nanokompozitnih sustava PU s 0,2, 1 i 3 \% punila MWCNT i MWCNT-COOH prikazane su na slici 5 .

Iz mikrografija prikazanih na slici 5 vidljivo je da se dodatkom oba punila znatno narušava krupna sferolitna morfologija PU-a. Proces kristalizacije i stvaranja sferolita pojednostavljeno se sastoji od faze nukleacije te rasta sferolita iz otopine ili taline. ${ }^{18}$ Čestice nanopunila uglavnom djeluju kao centri nukleacije odnosno dodatkom čestica nanopunila povećava se prosječna gustoća sferolita, dok se njihova veličina smanjuje. Dodatak nanopunila različito utječe na brzinu rasta sferolita. Ovisno o kompozitnom sustavu brzina rasta sferolita može se povećavati, smanjivati ili ostati nepromijenjena, što je u ovom radu istraženo $u$ izotermnim i neizotermnim uvjetima tehnikom DSC. Neovisno kako punilo djeluje na nukleaciju ili kinetiku kristalizacije, u gotovo svim sustavima dodatkom nanopunila smanjuje se veličina sferolita, što je uzrokovano steričkim smetnjama koje uzrokuju čestice nanopunila. Stoga sferoliti dostižu veličinu usporedivu s razmakom između čestica ili agregata punila. ${ }^{18}$ Prema tome, čestice punila MWCNT i MWCNT-COOH su heterogeni centri nukleacije u matrici PU koji ometaju rast sferolita, te stoga na mikrografijama nanokompozita nisu vidljivi krupni sferoliti kao kod PU-a. Slične promjene u morfologiji dobivene su i u kompozitima poliuretana i amorfne silike. ${ }^{19}$

Na slici 5 je također vidljivo da modifikacija MWCNT-a utječe na raspodijeljenost u matrici PU. Na slikama se može uočiti da se bolja raspodjela punila unutar matrice PU postiže u sustavu s modificiranim MWCNT-COOH-om. Također je vidljivo da dolazi do djelomičnog taloženja
MWCNT-a i MCWNT-COOH-a u masi uzorka, što je znatnije izraženo u sustavima s punilom MWCNT. Na slici 6 prikazani su uzorci dobiveni nakon sušenja na kojima je i na površini filma PU/MWCNT 0,2 \% vidljiva agregiranost po cijelom uzorku kompozita, što je uočeno u sustavima sa svim udjelima punila MWCNT. Za razliku od sustava PU s punilom MWCNT, filmovi s punilom MWCNT-COOH na mikrorazini su glatki i homogeni. Kako je poznato, nanopunila su izrazito sklona agregaciji što više dolazi do izražaja povećanjem količine punila MWCNT i MWCNT-COOH u sustavu. Veće agregiranje nanopunila vidljivo je u sustavima PU/MWCNT.

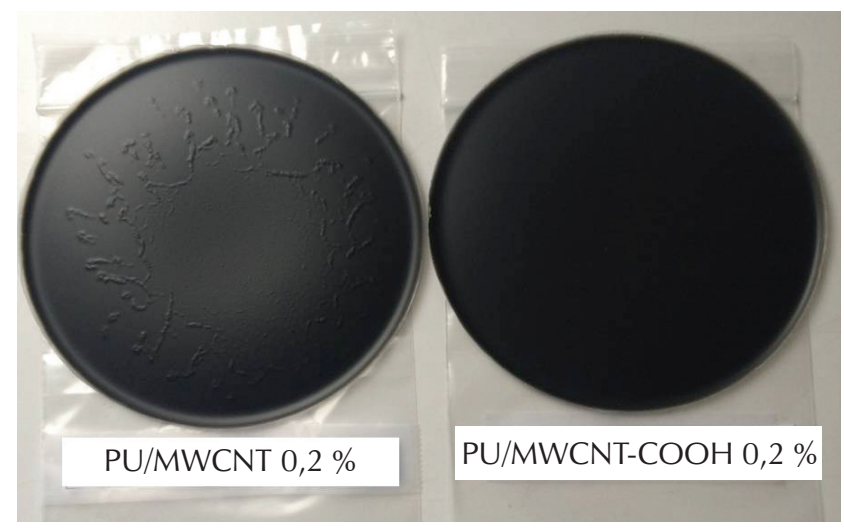

Slika 6 - Filmovi nanokompozita s 0,2 \% MWCNT-a i 0,2 \% punila MWCNT-COOH

Fig. 6 - Nanocomposite films with $0.2 \%$ of MWCNT and $0.2 \%$ of MWCNT-COOH filler 
Utjecaj modifikacije površine MWCNT-a sa skupinama $\mathrm{COOH}$ na raspodijeljenost u matrici PU može se objasniti s dva razloga. Prvi razlog u razmatranje uključuje mogućnost da je u otopini PU-a u acetonu prije sušenja filma punilo MWCNT zbog svoje nepolarne prirode ipak slabije raspodijeljeno bez obzira što iz slike 3 nije vidljiva znatnija razlika u dispergiranosti. Drugi razlog može se pripisati međudjelovanjima između skupina $\mathrm{COOH}$ na površini MWCNT-a i esterskih karbonilnih skupina u poliuretanskom lanca te smanjivanjem van der Waalsovih sila između MWCNT-COOH, što omogućava bolju dispergiranost.

\subsection{Toplinska svojstva PU nanokompozita u neizotermnim uvjetima}

Toplinska svojstva poliuretana, PU/MWCNT i PU/MWCNT- $\mathrm{COOH}$ nanokompozita istraživana su diferencijalnom pretražnom kalorimetrijom (DSC) u neizotermnim uvjetima. Rezultati ranijih istraživanja ${ }^{20}$ toplinskih svojstava tehnikom DSC pokazali su da segmentirani poliuretani imaju tri prijelaza u rasponu od $-100{ }^{\circ} \mathrm{C}$ do $250{ }^{\circ} \mathrm{C}$. Prvi prijelaz u temperaturnom području od $-31{ }^{\circ} \mathrm{C}$ do $-29{ }^{\circ} \mathrm{C}$ pripisuje se staklištu mekih segmenata. Endotermni prijelaz pri temperaturi $41{ }^{\circ} \mathrm{C}$ do $43{ }^{\circ} \mathrm{C}$ talište je mekih segmenata, a prijelaz pri $195{ }^{\circ} \mathrm{C}$ do $205^{\circ} \mathrm{C}$ talište je tvrdih segmenata.

Na slici 7 prikazani su termogrami ciklusa hlađenja te drugog zagrijavanja poliuretana. U ciklusu hlađenja vidljiv je egzotermni pik pri temperaturi oko $-6{ }^{\circ} \mathrm{C}$ koji se pripisuje kristalizaciji mekih segmenata poliuretana. $U$ drugom ciklusu zagrijavanja nakon staklastog prijelaza mekih segmenata $\left(\vartheta_{\mathrm{g}}\right)$ pri temperaturi $-46,4{ }^{\circ} \mathrm{C}$ pojavljuje se egzotermni pik hladne kristalizacije pri temperaturi $-9,1{ }^{\circ} \mathrm{C}$, što upućuje na to da u procesu hlađenja pri $10{ }^{\circ} \mathrm{C} \mathrm{min}^{-1}$ poliuretan nije potpuno iskristalizirao. Nakon hladne kristalizacije vidljiv je endotermni pik taljenja kristalne faze pri temperaturi $42,7{ }^{\circ} \mathrm{C}$. U preliminarnom eksperimentu u širem temperaturnom rasponu ovaj uzorak PU-a nije pokazao očekivani pik taljenja tvrdih polarnih segmenata vjerojatno zbog njihova malog udjela.

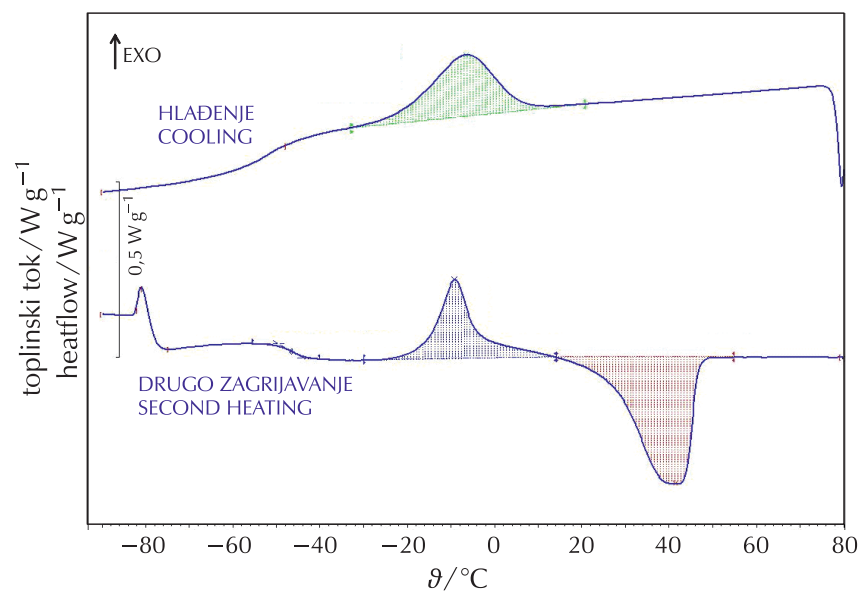

Slika 7 - DSC termogram poliuretana u neizotermnim uvjetima

Fig. 7 - DSC thermogram of polyurethane under non-isothermal conditions
Za analizu utjecaja punila MWCNT i MWCNT-COOH na promjene temperatura i entalpija prijelaza analizirane su vrijednosti ciklusa hlađenja te drugog ciklusa zagrijavanja. Iz termograma za odabrane nanokompozitne sustave prikazanih na slici 8 vidljivo je da dodatak punila MWCNT i MWCNT-COOH znatno utječe na toplinska svojstva matrice PU.

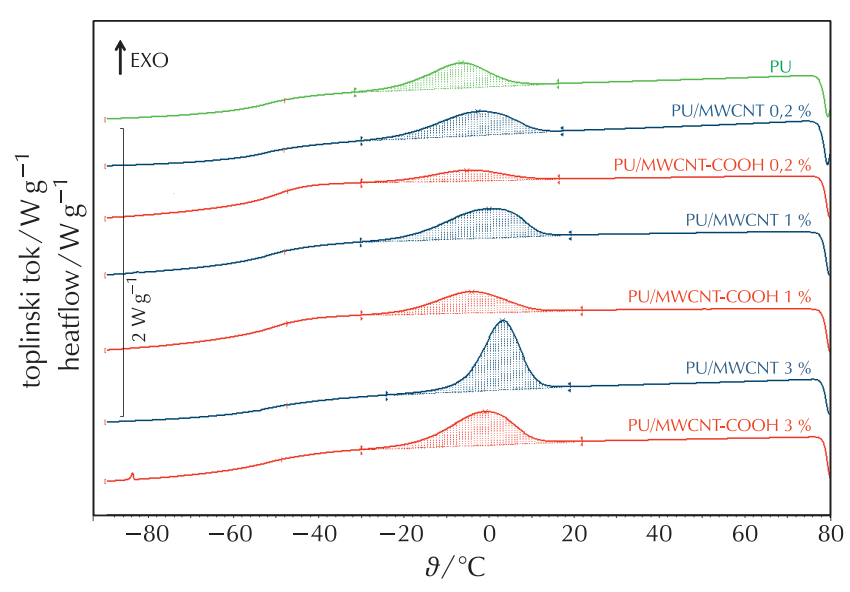

Slika 8 - Termogrami ciklusa hlađenja za PU i nanokompozite s 0,2, 1 i $3 \%$ punila MWCNT i MWCNT-COOH

Fig. 8 - Thermograms of PU and nanocomposites with $0.2,1$, and $3 \%$ of MWCNT and MWCNT-COOH filler obtained during cooling run

Značajka krivulja DSC istraživanih sustava, određena kao temperatura vrška procesa kristalizacije, prikazana je na slici 9. Iz dobivenih rezultata vidljivo je da dodatkom punila kristalizacija mekog segmenta započinje pri višim temperaturama u odnosu na PU, što znači da punila ubrzavaju kristalizaciju. Taj učinak punila znatnije je izražen za sustave s MWCNT-om nego s MWCNT-COOH-om.

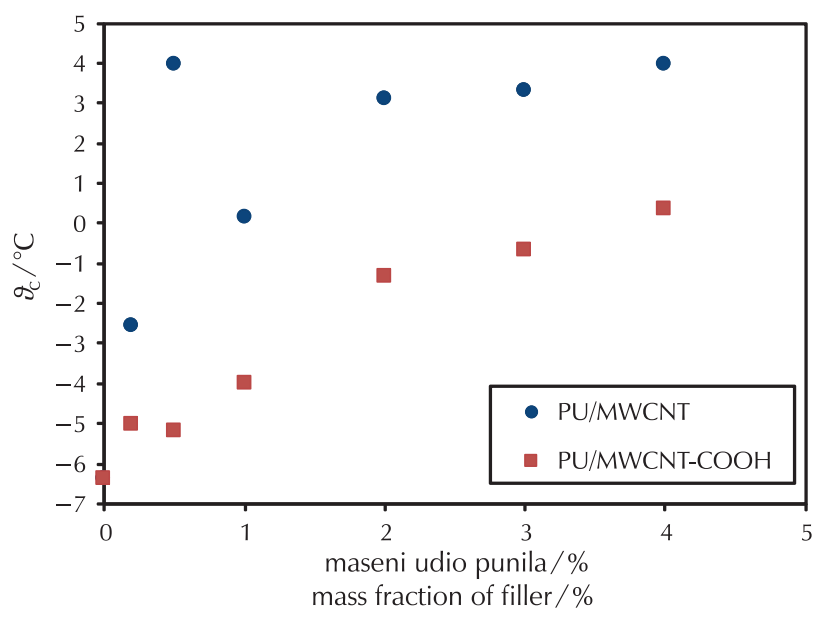

Slika 9 - Temperatura kristalizacije nanokompozita PU u procesu hlađenja

Fig. 9 - Crystallization temperature of PU nanocomposites obtained during cooling run 
Povećanjem količine punila MWCNT entalpija kristalizacije se povećava u cijelom rasponu ispitivanih koncentracija. Dodatkom manjih količina punila MWCNT-COOH entalpija se smanjuje u odnosu na PU, a daljnjim povećanjem udjela se povećava (slika 10). Iz dobivenih rezultata može se zaključiti da punilo MWCNT u cijelom rasponu udjela potiče kristalizaciju mekog segmenta matrice PU, dok punilo MWCNT-COOH do masenog udjela $1 \%$ otežava, a kod većih udjela također potiče kristalizaciju.

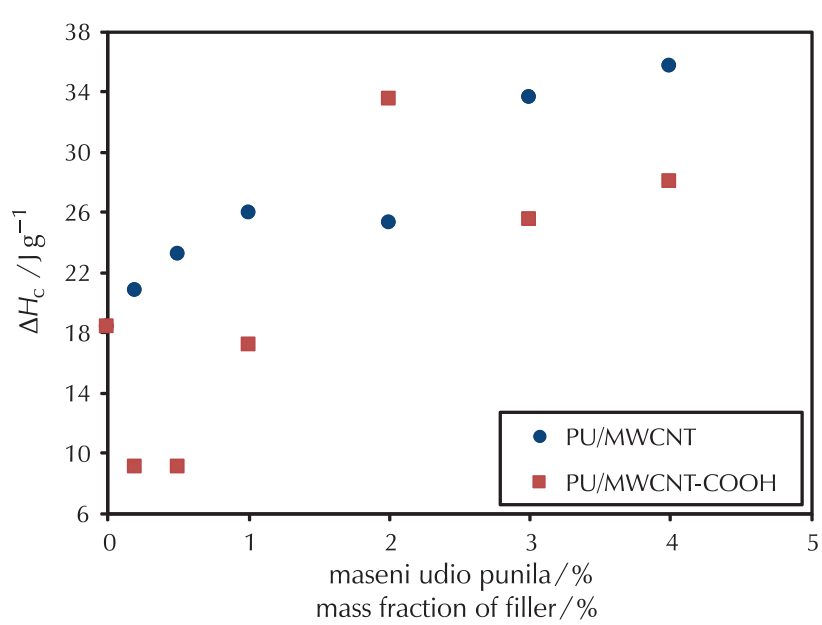

Slika 10 - Entalpija kristalizacije nanokompozita PU u procesu hlađenja

Fig. 10 - Crystallization enthalpy of PU nanocomposites during cooling

S obzirom na to da je termoplastični poliuretan vrlo kompleksne strukture, odnosno da sadrži meku nepolarnu i tvrdu polarnu fazu, za objašnjenje dobivenih rezultata potrebno je uzeti u obzir brojne čimbenike. Prema dosadašnjim istraživanjima razlika između utjecaja punila MWCNT i MWCNT-COOH na kristalnost matrice PU može se povezati s četiri učinka. Prvi učinak je dispergiranost tih nanopunila u poliuretanskoj matrici. Iz mikrografija prikazanih na slici 5 vidljivo je da je u matrici PU punilo MWCNT-COOH bolje raspodijeljeno nego MWCNT, što znači da bi punilo MWCNT-COOH trebalo imati znatniji učinak na homogenost same matrice te posljedično i na stupanj kristalnosti. Drugi učinak je jačina međudjelovanja između punila i matrice na razdvajanje meke i tvrde domene poliuretana. Slično kao skupina $\mathrm{OH}$ na površini silika-punila, ${ }^{21-23}$ skupina $\mathrm{COOH}$ na površini MWCNT-a može uspostavljati međudjelovanja s esterskim karbonilnim skupinama matrice PU te potaknuti odvajanje mekog i tvrdog segmenta i time omogućiti veću kristalnost mekog segmenta matrice PU. Treći učinak razmatra stupanj kristalnosti sa stanovišta kompatibilnosti mekog segmenta matrice PU koji kristalizira i nanopunila, prema kojem se može očekivati da će zbog hidrofobnog karaktera površine punila MWCNT i hidrofobnosti mekog segmenta to punilo imati znatniji učinak na kristalizaciju te faze tijekom hlađenja. Četvrti učinak uključuje vrstu funkcijskih skupina na stijenci punila MWCNT. Ranija istraživanja ${ }^{24}$ utjecaja MWCNT-a, MWCNT-COOH-a, MWCNT-F-a i MWCNT-OH-a na kristalizaciju polilaktida (PLA) pokazala su da prisutnost funkcijskih skupina na površini MWCNT-a smanjuje nukleacijski učinak MWCNT-a kao i kristalnost matrice PLA. Smanjenje nukleacijskog učinka, osim o međudjelovanjima funkcijskih skupine s matricom, ovisi i o steričkim smetnjama, odnosno o veličini funkcijskih skupine. U skladu s tim rezultatima može se očekivati da će MWCNT imati znatniji učinak na brzinu i kristalnost matrice PU budući da skupine $\mathrm{COOH}$ na površini punila MWCNT-COOH sterički ometaju kristalizaciju PU-a.

Iz rezultata dobivenih u ovom radu vidljivo je da MWCNT u odnosu na MWCNT-COOH ima znatniji učinak na proces kristalizacije mekog segmenta PU-a, odnosno da prevladavaju treći i četvrti učinak.

Iz termograma drugog ciklusa zagrijavanja odabranih uzoraka vidljive su razlike koje tijekom tog procesa uzrokuje dodatak punila MWCNT i MWCNT-COOH (slika 11). $\mathrm{U}$ drugom ciklusu zagrijavanja nakon staklišta u procesu hladne kristalizacije kristalizira dio matrice PU koji nije iskristalizirao u procesu hlađenja.

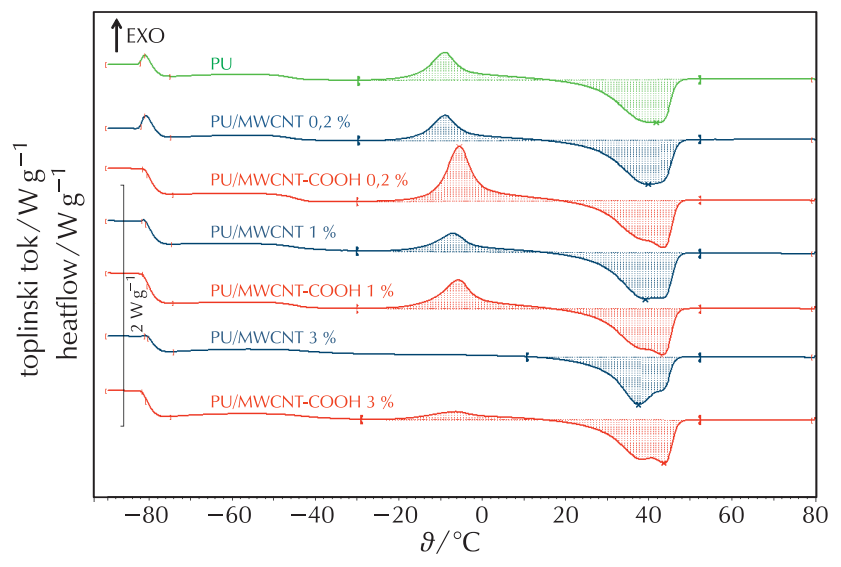

Slika 11 - Termogrami ciklusa drugog zagrijavanja za poliuretan i nanokompozitne sustave s $0,2,1$, i 3 \% punila MWCNT i MWCNT-COOH

Fig. 11 - Thermograms of polyurethane and nanocomposites with $0.2,1$, and $3 \%$ MWCNT and MWCNT-COOH filler obtained during second heating run

Do hladne kristalizacije dolazi jer nakon staklastog prijelaza molekulski lanci poliuretana imaju dovoljnu fleksibilnost da kristaliziraju. Iz dobivenih termograma analizirane su promjene temperatura i entalpija hladne kristalizacije i taljenja uzrokovane povećanjem udjela punila MWCNT i MWCNT-COOH. Na slici 12 vidljivo je da se vrijednosti temperatura vrška hladne kristalizacije pomiču prema višim temperaturama $\left(-9{ }^{\circ} \mathrm{C}\right.$ do $\left.-5{ }^{\circ} \mathrm{C}\right)$ s obzirom na čisti PU. lako, općenito, porast temperature hladne kristalizacije znači da se usporava proces kristalizacije, u ovom istraživanju potrebno je uzeti u obzir da se povećanjem količine nanopunila mijenja udio faze koja kristalizira tijekom hlađenja (slika 10), što znači da u ciklusu zagrijavanja preostaje udio mekog segmeta koji teže kristalizira. Stoga se povećanje temperature hladne kristalizacije može pripisati tom učinku, a ne usporavanju procesa hladne kristalizacije dodatkom nanopunila. 


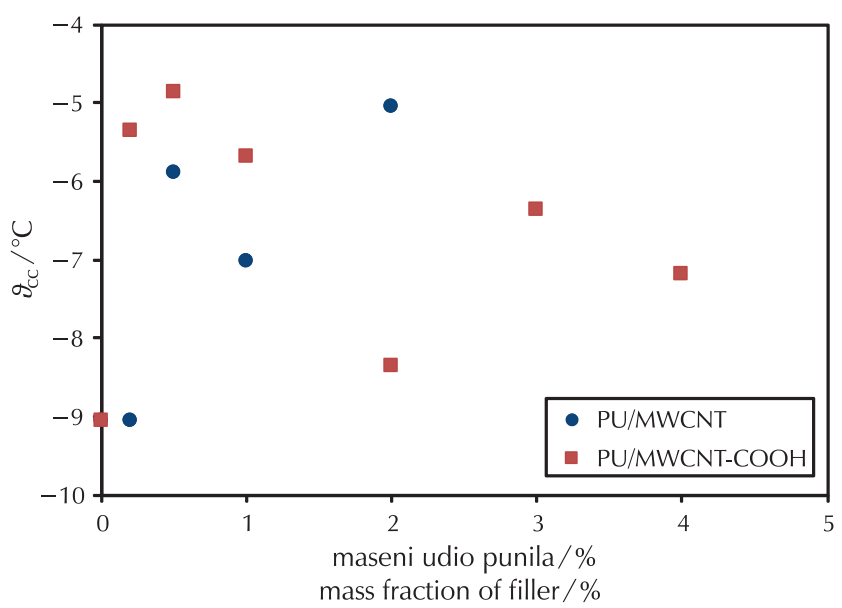

Slika 12 - Temperature hladne kristalizacije nanokompozita PU u procesu drugog zagrijavanja

Fig. 12 - Cold crystallization temperature of PU nanocomposites during second heating run

Karakteristične vrijednosti entalpije hladne kristalizacije u ovisnosti o masenom udjelu punila prikazane su na slici 13. Vrijednosti entalpija hladne kristalizacije istraživanih sustava ovise o udjelu meke faze koji je iskristalizirao tijekom hlađenja. Dakle, može se očekivati da je za sustave, kojima je veći udio iskristalizirao u fazi hlađenja, vrijednost entalpije hladne kristalizacije manja.

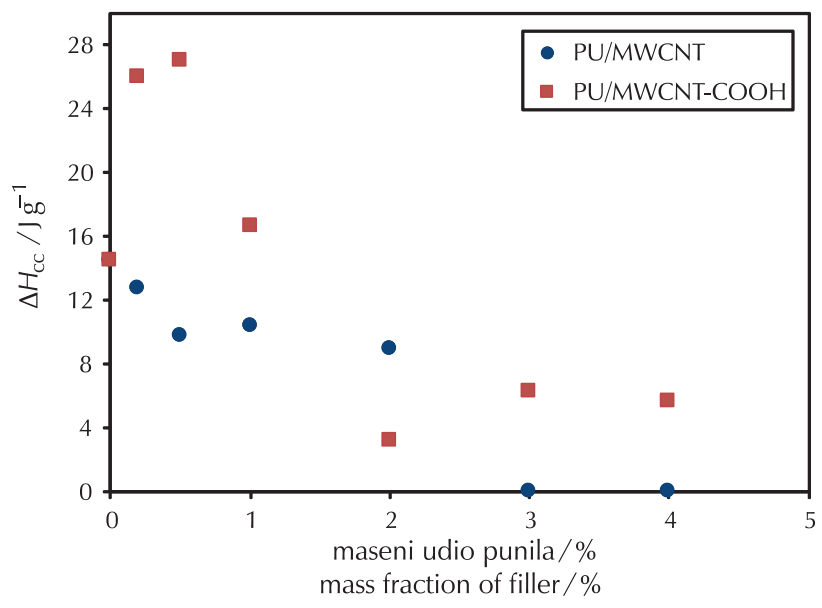

Slika 13 - Entalpija hladne kristalizacije nanokompozita PU u procesu zagrijavanja

Fig. 13 - Enthalpy of cold crystallization of PU nanocomposites during second heating run

Vrijednosti temperatura taljenja upućuju na uređenost kristalne faze, odnosno vrijedi da uređenija kristalna faza ima višu temperaturu taljenja. Analiza rezultata temperatura vrška taljenja pokazala je da nema znatnije razlike dodatkom nanopunila. Međutim, uočena je razlika u obliku pika taljenja. Na slici 11 vidljivo je da čisti PU i nanokompozit PU/MWCNT 0,2 \% imaju jednostruki široki pik. U svim ostalim nanokompozitnim sustavima vidljivi su dvostruki pikovi taljenja što upućuje da nastaju strukture različitog stupnja uređenosti lanaca matrice PU. Usporedbom pikova taljenja sustava s 1 i 3 \% uočava se da je za sustave s nanopunilom MWCNT izraženiji pik pri nižim temperaturama, dok je za sustave s punilom MWCNT-COOH izraženiji pik pri višim temperaturama. Stoga se, iako se temperature pikova znatnije ne razlikuju, ipak može zaključiti da u sustavima s punilom MWCNT u odnosu na sustave s punilom MWCNT-COOH nastaje veći udio slabije uređene kristalne faze mekog segmenta matrice PU.

lako se povećanjem udjela nanopunila ne uočava pravilan slijed entalpije taljenja (slika 14), rezultati pokazuju da nanopunila MWCNT i MWCNT-COOH potiču kristalizaciju mekog segmenta matrice PU za maksimalno oko $10 \%$.

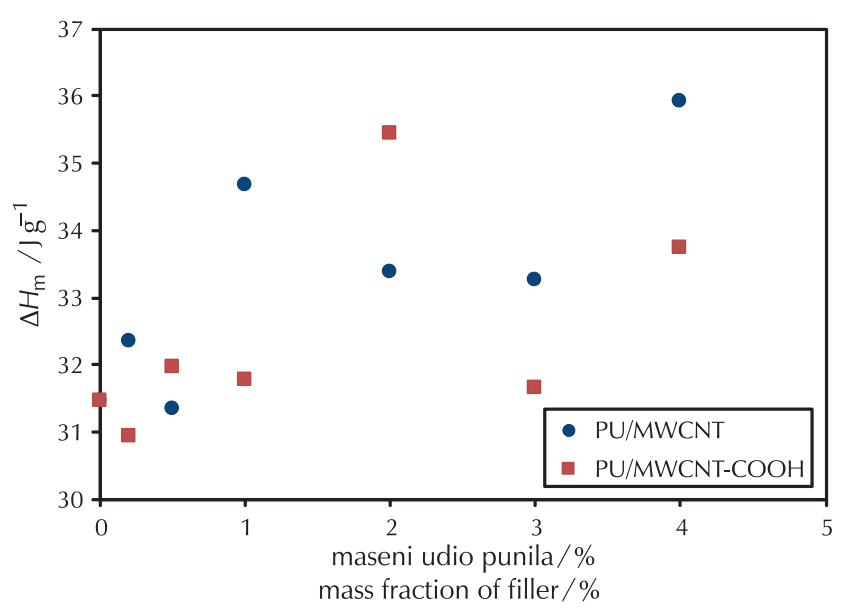

Slika 14 - Entalpija taljenja nanokompozita PU u procesu drugog zagrijavanja

Fig. 14 - Melting enthalpy of PU nanocomposites during second heating run

\subsection{Toplinska svojstva nanokompozita PU pri izotermnim uvjetima}

Dodatak punila može imati znatan utjecaj na kristalnost polimerne matrice i kinetiku kristalizacije. Punilo može biti centar nukleacije te stoga ubrzavati kristalizaciju ili usporavati kristalizaciju, što ovisi o vrsti punila, raspodijeljenosti punila u polimernoj matrici i količini dodanog punila. Ranija istraživanja utjecaja MWCNT-a na kristalizaciju poli(3hidroksibutirata) (PHB ${ }^{25}$ pokazala su da se ukupna brzina kristalizacije na određenoj temperaturi izotermne kristalizacije povećava dodatkom MWCNT-a. Ubrzanje procesa kristalizacije pripisuje se nukleacijskom učinku MWCNT-a.

U ovom radu istraživana je kristalizacija poliuretana i nanokompozita u izotermnim uvjetima pri temperaturi izotermne kristalizacije $-3{ }^{\circ} \mathrm{C}$. Na slici 15 prikazane su krivulje izotermne kristalizacije pri temperaturi $-3{ }^{\circ} \mathrm{C}$ za odabrane nanokompozite, na kojima su vidljivi egzotermni pikovi kristalizacije. Iz krivulja izotermne kristalizacije također je vidljivo da se povećanjem udjela oba punila entalpija izotermne kristalizacije znatno smanjuje. Ti rezultati ukazuju da se unatoč velikoj brzini hlađenja tijekom prethodnog ciklusa $\left(50{ }^{\circ} \mathrm{C} \mathrm{min}^{-1}\right)$ dogodila djelomična kristalizacija 
mekog segmenta matrice PU, što je u skladu s rezultatima neizotermne kristalizacije.

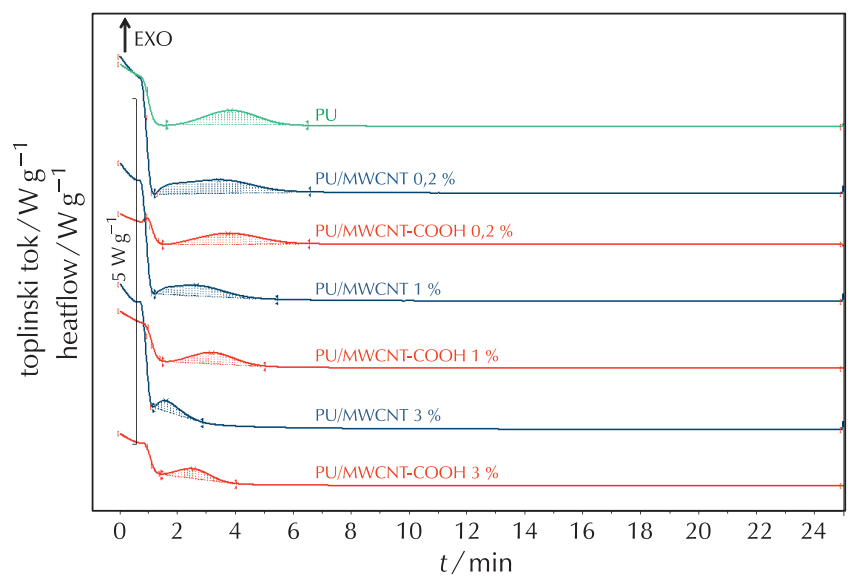

Slika 15 - Krivulje izotermne kristalizacije pri temperaturi $-3{ }^{\circ} \mathrm{C}$ za poliuretan i nanokompozitne sustave s 0,2, 1, i $3 \%$ punila MWCNT i MWCNT-COOH

Fig. 15 - Thermograms of isothermal crystallization at temperature of $-3{ }^{\circ} \mathrm{C}$ for polyurethane and nanocomposites with $0.2,1$, and $3 \%$ of MWCNT and MWCNT-COOH fillers

Iz dobivenih krivulja određeno je vrijeme za postizanje maksimuma pika izotermne kristalizacije mekog segmenta matrice PU koje je mjera brzine kristalizacije (slika 16).

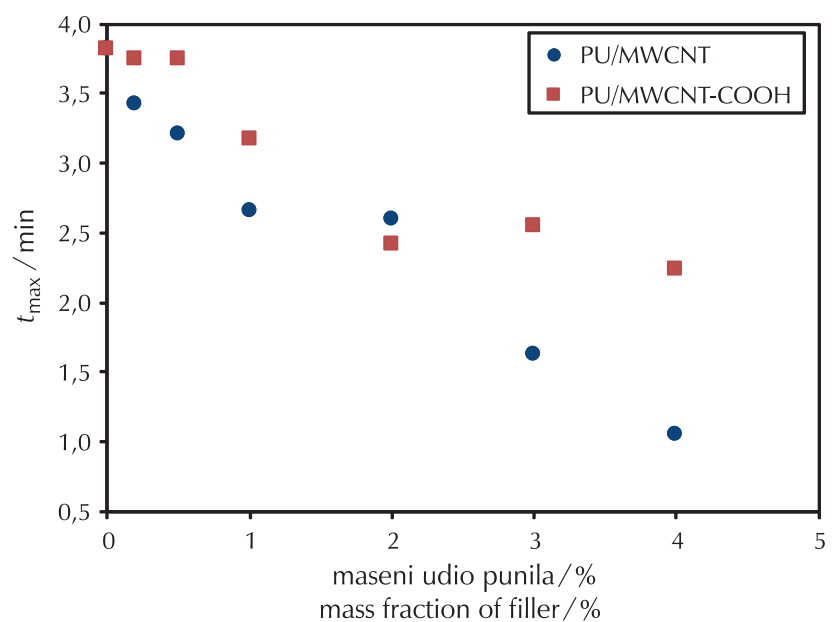

Slika 16 - Vrijeme maksimuma pika izotermne kristalizacije za sustave PU/MWCNT i PU/MWCNT-COOH

Fig. 16 - Time at maximum of isothermal crystallization peak for PU/MWCNT and PU/MWCNT-COOH nanocomposites

Kako je vidljivo na slici 16, povećanjem udjela punila pikovi kristalizacije mekog segmenta matrice PU pomiču se prema kraćim vremenima, što upućuje na povećanje brzine kristalizacije mekog segmenta PU-a s porastom udjela punila, odnosno oba nanopunila imaju nukleacijski učinak, koji je jače izražen za MWCNT. Mogući razlozi jačem nukleacijskom učinku isti su kao kod analize rezultata neizotermne kristalizacije.

\section{Zaključak}

U okviru ovog rada istražen je učinak dodatka punila MWCNT i MWCNT-COOH na morfologiju i toplinska svojstva termoplastične poliuretanske matrice. Rezultati određivanja kontaktnog kuta s vodom pokazali su da modifikacija ugljikovih nanocjevčica skupinama $\mathrm{COOH}$ mijenja karakter površine iz hidrofobne u hidrofilnu.

Iz optičkih polarizacijskih mikrografija uočeno je da se dodatkom oba punila gubi krupna sferolitna morfologija matrice PU te da je punilo MWCNT-COOH bolje raspodijeljeno u matrici PU.

Rezultati DSC-a u neizotermnim i izotermnim uvjetima pokazali su da dodatak punila MWCNT i MWCNT-COOH znatno utječe na toplinska svojstva matrice PU. Oba punila ubrzavaju kristalizaciju mekog nepolarnog segmenta i povećavaju kristalnost matrice PU u neizotermnim i izotermnim uvjetima. Unatoč slabijoj raspodijeljenosti punila MWCNT, taj učinak znatnije je izražen za sustave PU s tim punilom nego s punilom MWCNT-COOH, što se može pripisati boljoj kompatibilnosti između nepolarnog punila MWCNT i nepolarne faze matrice PU, kao i činjenici da skupine na površini MWCNT-a, u ovom slučaju skupine $\mathrm{COOH}$, smanjuju nukleacijski učinak tog nanopunila. Analizom pikova taljenja nakon faze zagrijavanja može se zaključiti da u sustavima PU s punilom MWCNT u odnosu na sustave s punilom MWCNT-COOH nastaje veći udio slabije uređene kristalne faze mekog segmenta matrice PU.

\footnotetext{
Popis kratica i simbola List of abbreviations and symbols

DSC - diferencijalna pretražna kalorimetrija

- differential scanning calorimetry

MWCNT - višestjene ugljikove nanocijevčice

- multiwalled carbon nanotubes

MWCNT-COOH - višestjene ugljikove nanocjevčice modificirane skupinama $\mathrm{COOH}$

- multiwalled carbon nanotubes modified with $\mathrm{COOH}$ groups

PU - poliuretan

- polyurethane

SWCNT - jednostjene ugljikove nanocjevčice

- singlewalled carbon nanotubes

$\Delta H_{\mathrm{c}} \quad-$ entalpija kristalizacije tijekom hlađenja, $\mathrm{Jg}^{-1}$

- crystallization enthalpy during cooling, J g ${ }^{-1}$

$\Delta H_{\mathrm{cc}} \quad-$ entalpija hladne kristalizacije tijekom zagrijavanja, $\mathrm{Jg}^{-1}$

- cold crystallization enthalpy during heating, $\mathrm{Jg}^{-1}$

$\Delta H_{\mathrm{m}} \quad-$ entalpija taljenja u procesu zagrijavanja, $\mathrm{Jg}^{-1}$

- melting enthalpy during heating, $\mathrm{Jg}^{-1}$
} 
$t_{\max }$

- vrijeme za postizanje maksimuma pika izotermne kristalizacije, min

- time at maximum of isothermal crystallization peak, min

$\theta$

$\vartheta_{\mathrm{C}}$

- kontaktni kut,

- contact angle,

- temperatura kristalizacije tijekom hlađenja, ${ }^{\circ} \mathrm{C}$

- crystallization temperature during cooling, ${ }^{\circ} \mathrm{C}$

$\vartheta_{\mathrm{CC}}$

- temperatura hladne kristalizacije tijekom zagrijavanja, ${ }^{\circ} \mathrm{C}$

- cold crystallization temperature during heating, ${ }^{\circ} \mathrm{C}$

\section{Literatura \\ References}

1. Z. S. Petrović, J. Ferguson, Polyurethane elastomers, Prog. Polym. Sci. 16 (1991) 695-836, doi: https://doi. org/10.1016/0079-6700(91)90011-9.

2. P. Krol, Synthesis methods, chemical structures and phase structures of linear polyurethanes. Properties and applications of linear polyurethanes in polyurethane elastomers, copolymers and ionomers, Prog. Mater. Sci. 52 (2007) 9151015, doi: https://doi.org/10.1016/j.pmatsci.2006.11.001.

3. L. S. Schadler, Polymer-based and polymer-filled nanocomposites, u P. M. Ajayan, L. S. Schadler, P. V. Braun, Nanocomposite Science and Technology, Wiley-VCH GmbH \& KGaA, Weinheim, 2003, str. 77-154.

4. V. Kovačević, D. Vrsaljko, S. Lučić Blagojević, M. Leskovac, Adhesion parameters at the interface in nanoparticulate filled polymer systems, Polym. Eng. Sci. 48 (2008) 19942002, doi: https://doi.org/10.1002/pen.21132.

5. D. Vrsaljko, M. Leskovac, S. Lučić Blagojević, V. Kovačević, Interphase phenomena in nanoparticulate filled polyurethane/ poly(vinyl acetate) polymer systems, Polym. Eng. Sci. 48 (2008) 1931-1938, doi: https://doi.org/10.1002/pen.21055.

6. V. Kovačević, M. Leskovac, S. Lučić Blagojević, Complex Adhesion Effects of Inorganic Nanofillers vs Microfillers in Polymer Composites, Macromol. Symp. 221 (2005) 11-22, doi: https://doi.org/10.1002/masy.200550302.

7. N. Tomczak, D. Janczewski, M. Han, G. Julius Vancso, Designer polymer-quantum dot architectures, Prog. Polym. Sci. 34 (2009) 393-340, doi: https://doi.org/10.1016/j.progpolymsci.2008.11.004.

8. P. J. F. Harris, Carbon nanotube science, Cambridge University Press, Cambridge, 2009, str.146-203.

9. S. H. Jin, D. K. Choi, D. S. Lee, Electrical and rheological properties of polycarbonate/multiwalled carbon nanotube nanocomposites, Colloids and Surfaces A: Physicochem. Eng. Aspects 313-314 (2008) 242-245, doi: https://doi. org/10.1016/j.colsurfa.2007.04.104.

10. F. H. Gojny, K. Schulte, Functionalisation effect on the thermo-mechanical behaviour of multi-wall carbon nanotube/epoxy-composites, Compos. Sci. Technol. 64 (2004) 2303-2308, doi: https://doi.org/10.1016/j.compscitech.2004.01.024.

11. Z. Xu, Y. Niu, L. Yang, W. Xie, H. Li, Z. Gan, Z. Wang, Morphology, rheology and crystallization behavior of polylactide composites prepared through addition of five-armed star polylactide grafted multiwalled carbon nanotubes, Polymer 51 (2010) 730-737, doi: https://doi.org/10.1016/j.polymer.2009.12.017.
12. S. H. Park, S. G. Lee, S. H. Kim, Isothermal crystallization behavior and mechanical properties of polylactide/carbon nanotube nanocomposites, Compos. Pt. A-Appl. Sci. Manuf. 46 (2013) 11-18, doi: https://doi.org/10.1016/j.compositesa.2012.10.011.

13. E. Logakis, E. Pollatos, Ch. Pandis, V. Peoglos, I. Zuburtikudis, C. G. Delides, A. Vatalis, M. Gjoka, E. Syskakis, K. Viras, P. Pissis, Structure-property relationships in isotactic polypropylene/multi-walled carbon nanotubes nanocomposites, Compos. Sci. Technol. 70 (2010) 328-335, doi: https://doi. org/10.1016/j.compscitech.2009.10.023.

14. M. S. Mohlala, S. S. Ray, Preparation and Characterization of Polymer/Multi-walled Carbon Nanotube Nanocomposites, Solid State Phenomena 140 (2008) 97-102, doi: https://doi. org/10.4028/www.scientific.net/SSP.140.97.

15. L. Song, Z. Qiu, Crystallization behavior and thermal property of biodegradable poly(butylene succinate)/functional multi-walled carbon nanotubes nanocomposite, Polym. Degrad. Stabil. 94 (2009) 632-637, doi: https://doi.org/10.1016/j. polymdegradstab.2009.01.009.

16. C.-S. Wu, H.-T. Liao, Study on the preparation and characterization of biodegradable

17. polylactide/multi-walled carbon nanotubes nanocomposites, Polymer 48 (2007) 4449-4458, doi: https://doi. org/10.1016/j.polymer.2007.06.004.

18. S. A. Shokry, A. K. El Morsi, M. S. Sabaa, R. R. Mohamed, H. E. El Sorogy, Synthesis and characterization of polyurethane based on hydroxyl terminated polybutadiene and reinforced by carbon nanotubes, Egyptian Journal of Petroleum 24 (2015) 145-154, doi: https://doi.org/10.1016/j. ejpe.2015.05.008.

19. E. Manias, G. Polizos, H. Nakajama, M. J. Heidecker, Fundamentals of polymer nanocomposite technology u C. Wilkie, A. Morgan (ur.), Flame retardant polymer nanocomposites, Wiley \& Sons, New York, 2007, str. 31-66.

20. S. Lučić Blagojević, Z. Buhin, A. Pustak, R. Lukić Kovačić, Influence of nanosilica on the morphology, thermal and mechanical properties of polyurethane elastomer, J. App. Polym. Sci. 125 (2012) E181-E190, doi: https://doi.org/10.1002/ app.36290.

21. J. Foks, H. Janik, R. Russo, Morphology, thermal and mechanical properties of solution - cast polyurethane films, Polymer 26 (1990) 309-314, doi: https://doi.org/10.1016/00143057(90)90246-Z.

22. R. C. R. Nunes, J. L. C. Fonseca, M. R. Pereira, Polymer-filler interactions and mechanical properties of a polyurethane elastomer, Polym. Test. 19 (2000) 93-103, doi: https://doi. org/10.1016/S0142-9418(98)00075-0.

23. R. C. R. Nunes, R. A. Pereira, J. L. C. Fonseca, M. R. Pereira, X-ray studies on compositions of polyurethane and silica, Polym. Test. 20 (2001) 707-712, doi: https://doi. org/10.1016/S0142-9418(01)00007-1.

24. L. Bistričić, G. Baranović, M. Leskovac, E. Govorčin Bajsić, Hydrogen bonding and mechanical properties of thin films of polyether-based polyurethane-silica nanocomposites, Eur. Polym. J. 46 (2010) 1975-1987, doi: https://doi. org/10.1016/j.eurpolymj.2010.08.001.

25. Y.-Y. Liang, J.-Z. Xu, X.-Y. Liu, G.-J. Zhong, Z.-M. Li, Role of surface chemical groups on carbon nanotubes in nucleation for polymer crystallization: Interfacial interaction and steric effect, Polymer 54 (2013) 6479-6488, doi: https://doi. org/10.1016/j.polymer.2013.09.027.

26. C. Xu, Z. Qiu, Isothermal Melt Crystallization Kinetics Study of Biodegradable Poly(3-hydroxybutyrate)/Multiwalled Carbon Nanotubes Nanocomposites, Polym. J. 41 (2009) 888892, doi: https://doi.org/10.1295/polymj.PJ2009114. 


\title{
EXTENDED ABSTRACT
}

\author{
Influence of Multiwalled Carbon Nanotube Modification \\ on Polyurethane Properties: I. Morphology and Thermal Properties \\ Sanja Lučić Blagojević, ${ }^{a^{*}}$ Martina Zeljko, and Anđela Pustak ${ }^{b}$
}

In this work, the influence of multiwalled carbon nanotubes (MWCNT) and carbon nanotubes modified with $\mathrm{COOH}$ groups $(\mathrm{MWCNT}-\mathrm{COOH})$ on the structure and properties of thermoplastic polyurethane (PU) were investigated. The samples of nanocomposite were prepared from a mixture of polyurethane and MWCNT in acetone by slow drying at room temperature. The effect of the addition of nanofillers on the spherulite structure of polyurethane and the distribution of the nanofillers in the PU matrix were analysed with optical polarization microscopy. Thermal properties in non-isothermal and isothermal conditions were investigated by differential scanning calorimetry (DSC).

The results of contact angle measurement imply that modification of MWCNT surface with $\mathrm{COOH}$ groups changes its surface from hydrophobic to hydrophilic (Fig. 2 and Table 1).

Optical polarization microscopy showed that the addition of both nanofillers disrupts the coarse spherulite morphology of the polyurethane matrix (Fig. 4 and Fig. 5). It was observed that, at the macro level, the modified MWCNT-COOH filler is better distributed in the PU matrix than is the MWCNT filler (Fig. 5).

The DSC results showed that, in non-isothermal conditions, up to a certain amount, both nanofillers accelerate the crystallization of the soft segments of polyurethane. This effect is more pronounced in systems with MWCNT filler (Fig. 9). The results of the crystallization enthalpy during cooling showed that MWCNT filler, despite its worse distribution in the PU matrix, more significantly enhances crystallization of PU's soft segment than does the MWCNT-COOH filler (Fig. 10). This conclusion can be ascribed to better compatibility between the nonpolar MWCNT filler and the nonpolar soft phase of the PU matrix, as well as to the previous scientific finding that functional groups at MWCNT surface decrease the nucleation effect of MWCNT. By analysing the melting peaks, it can be concluded that the PU systems with MWCNT compared to systems with MWCNT-COOH contain a higher proportion of less ordered crystalline soft phase (Fig. 11).

In isothermal conditions, the MWCNT filler accelerates crystallization more significantly than does the MWCNT-COOH filler (Fig. 16).

\section{Keywords}

Polyurethane, carbon nanotubes, nanocomposites, morphology, crystallinity, thermal properties

a University of Zagreb, Faculty of Chemical Engineering and Technology, Marulićev trg 19, 10000 Zagreb, Republic of Croatia

${ }^{b}$ Ruđer Bošković Institute, Bijenička cesta 54, 10000 Zagreb, Republic of Croatia
Original scientific paper Received November 18, 2016 Accepted February 22, 2017 